\title{
Tracing the Conceptual Framework of Multimedia- based Instructional Package for Enhancing English Language Skills
}

\author{
Hemant Lata Sharma ${ }^{1}$, Kiran Rani ${ }^{2}$ \\ ${ }^{1}$ Professor \& Dean, Faculty of Education, MDU, Rohtak. \\ ${ }^{2}$ Junior Research Fellow, Department of Education, MDU, Rohtak.
}

\begin{abstract}
English language is the leading language of international discourse and the lingua franca for economic, scientific, and political exchange. Therefore, command over the English language attains central place among the determinant of access to higher education and employment possibilities especially in a multilingual country like India. But traditionally "Chalk and Talk" method is used in Indian class-rooms, doesn't provide adequate exposure to master the English language skills. Multimedia based Instructional Package for Enhancing English Language Skills (MBIP-ELS), may prove to be quite useful. This paper traces the conceptual framework to design an effective MBIP-ELS as provided by Mayer's Multimedia Learning Theory.
\end{abstract}

Keywords: Multimedia-based Instructional Package (MBIP), English Language Skills (ELS), English as a Foreign Language (EFL), ESL (English as a Second Language), English Language Teaching (ELT).

\section{Introduction}

English language, today, is the leading language of international discourse and the lingua franca for economic, scientific, and political exchange as well as in professional contexts such as navigation and law. According to Crystal (2003), $85 \%$ of the world's international organizations use English as their official language in trans-national communications. About $85 \%$ of the world's important film productions and markets use English as well, and $90 \%$ of the published academic articles in several academic fields, such as linguistics, are written in English. It has second largest number of speakers in the world (340 million native speakers and 510 second language speakers) as per the 2015 edition of Ethnologue, a language reference published by SIL International.

In a multilingual country like India, where more than 1700 languages are spoken (as per census of India, 2001), English acts as a connecting link between different states. English, today, is considered a language of opportunity; providing access to knowledge, power and material possessions. - An understanding and command over the English language is the most important determinant of access to higher education, employment possibilities and social opportunities" (National Knowledge Commission, 2007). This has lead to the pan-Indian rush to learn English, cutting across all classes. Now a vast majority of urban as well as rural parents in India want their children to learn English. Both private and government-aided English medium schools have mushroomed to meet the increasing demand. This has significantly influenced the policy and practice of primary and secondary education in post independence India. The current educational policy in India allows twelve years of English learning before entering the world of higher education as English subject is compulsory from first to twelfth. However, instead of acquiring basic communication skills, most of them are unable to speak, read or write even basic sentences in English. Result is the abysmally low level of proficiency in English language, highlighted by the study undertaken by John Kurrien, Director of the Centre for Learning Resources, a Pune based NGO. In this study, the English language skills of 100 students in eight rural and two urban government regional medium schools were examined. These Class 10 students - most of them selected by their teachers as among the best in English were asked to write as much as possible about their favourite film star. About half of these "best" students were unable to write a single correct sentence, or at best could manage only one correct sentence. While less than 10 per cent were able to write more than five correct sentences" (Kurrien, 2008). This dearth of English language skills becomes a major hindrance in accessing higher education and exploring vocational possibilities, as highlighted by National Knowledge Commission (NKC).

School-leavers who are not adequately trained in English as a language are always at a handicap in the world of higher education. ... This disadvantage is accentuated further in the world of work, not only in professional occupations but also in white-collar occupations overall". (NKC, 2007)

In order to explore the factors responsible for this inefficiency, existing English learning and teaching (ELT) environment in India needs to be analysed. The primary factor affecting language acquisition appears to be the input that the learner receives. Stephen Krashen (2009) took a very strong position on the importance of input, asserting that comprehensible input is all that is necessary for secondlanguage acquisition. Input-rich communicational environments are a prerequisite for language learning. But how this input is planned and given is what actually makes a difference.

\section{ELT (English Language Teaching) in Indian classrooms}

Traditionally, in Indian classrooms, English is taught by -C Calk and Talk" method in which the focal points are the blackboard and the teacher's voice in contrast to the more informal child-centred activities. In Indian 


\section{International Journal of Science and Research (IJSR) \\ ISSN (Online): 2319-7064}

Index Copernicus Value (2013): 6.14 | Impact Factor (2014): 5.611

classrooms, teachers tend to focus on rote learning, errors or hard spots rather than on imaginative input and articulation. But human mind acquires a language in an environment that stimulates multiple brain systems. Therefore, a language classroom should be like a workshop where student is exposed to the opportunities of being actively involved in constructing the target language. To materialise this aim, technological innovations of the modern times offer ample opportunities. The devices like computer, laptop, internet, new software applications, and mobile devices such as smart phones, tablets, and digital cameras etc enable an instructor to design his instruction using a combination of various content forms such as text, image, audio, video, graphics, animation and interactive component which is termed as Multimedia. Multimedia can be integrated into daily classroom practice to go beyond chalk and talk ${ }^{6}$ and produce computer-based lesson plans compiling a series of presentations, text about a particular topic, and associated illustrations in various information formats. Multimedia authoring can support language acquisition through learning strategies such as creating visual projects, oral fluency practice, and opportunities for producing authentic language, helping students progress more quickly through the stages of language acquisition and achieve proficiency. Multimedia based Instructional Package for enhancing English language Skills (MBIP-ELS) can be constructed to make teaching and learning more interactive, collaborative, personalised, meaningful, and fun.

\section{Multimedia based Instructional Package for Enhancing English Language Skills (MBIP-ELS)}

\section{a) Meaning \\ Multimedia based Instructional Package for Enhancing English Language Skills (MBIP-ELS) is an instructional plan that utilises different content forms such as text, graphics, audio, video, still images, animation and interactive component to enhance English language skills viz listening, speaking, reading and writing. - Amultimedia Instructional message is a communication containing words}

and pictures intended to foster learning. The communication can be delivered using any media, including paper (i.e., book based communications) or computers (i.e. computer based communications). Words can include printed words or spoken words, pictures can include static graphics- such as illustrations or photos and dynamic graphics- such as animation or video clips" (Mayer, 2001). It is different from the media that use only rudimentary computer displays such as text-only or traditional forms of printed or hand-produced material. MBIP-ELS is usually recorded and played, displayed, or accessed by information content processing devices, such as computerized and electronic devices, but can also be part of a live performance.

\section{b) Components}

An MBIP-ELS comprises of digital lessons combining text, audio, image, video, animation and interactive component to master various structures, forms and rules of English grammar to ensure accuracy along with stories/drama/plays/poems in a combination of text, image, animation, audio or video format to enable meaningful listening, improve pronunciation and situational communication. It may also incorporate simulated conversations in various situations to develop functional language skills along with exercises combining different content forms to enable the students to actively construct the language in spoken or/and written form. This provides opportunities to improve vocabulary, pronunciation and practice language structures to stimulate meaningful listening, improve speaking skill, and ensure accuracy and speed in reading text and better expression in written form. It proposes way for learners to internalize a second language and to experiment in a classroom context. As the students are exposed to the target language rich media in an interesting and meaningful form, they become actively engaged in the process of language construction. The figure below depicts the components (overlapping in more ways than one) of a Multimedia based Instructional Package for Enhancing English Language Skills (MBIP-ELS): 


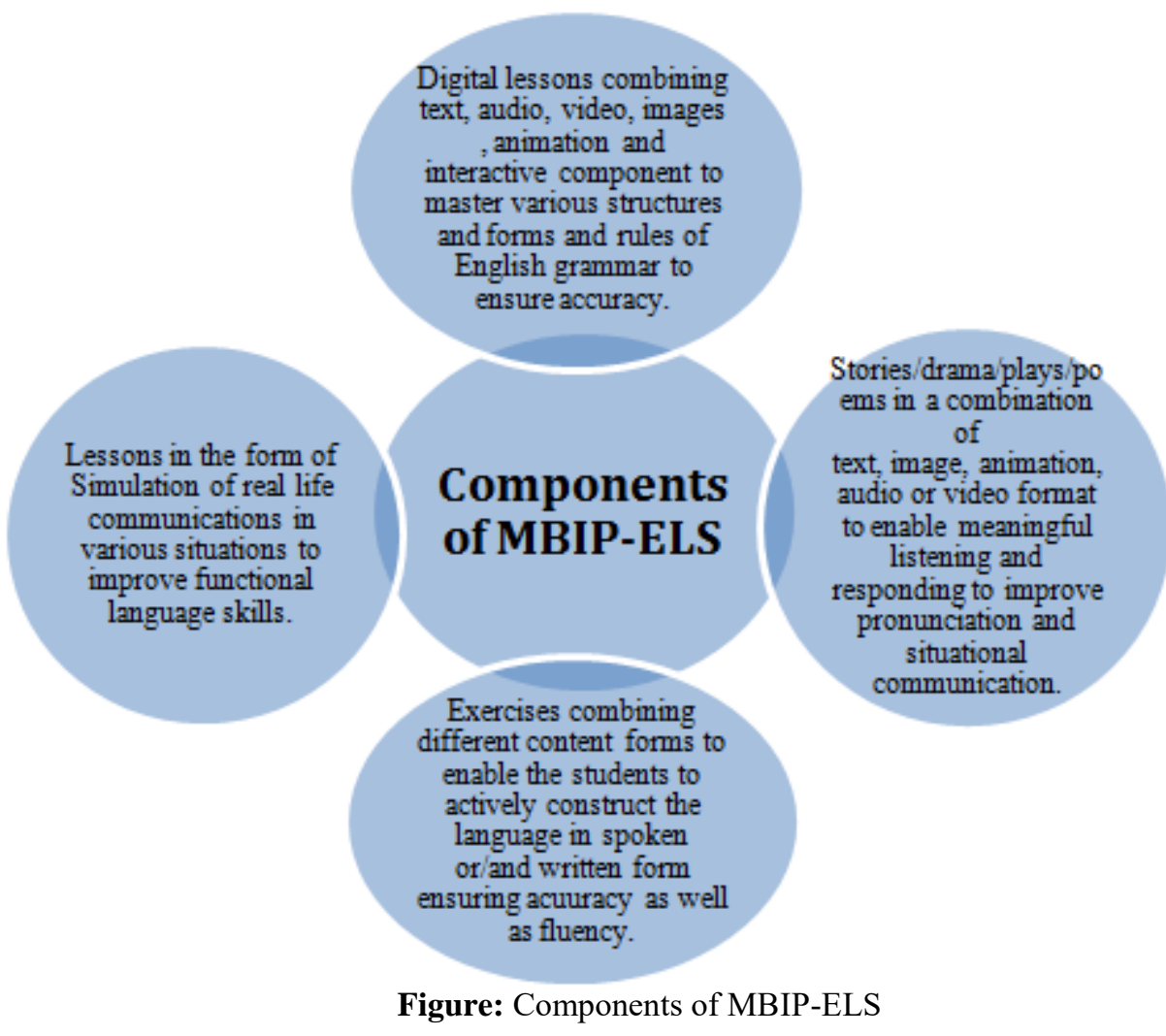

\section{Synthesis of Research Related to MBIP-ELS}

Since its introduction, Multimedia has been the most buzzing topic in the arena of research. So many studies have been conducted at different places on different age group of learners with different types of multimedia instruction patterns. Matlin (1989) found in his study that Multimedia applied in the language class can offer the authentic English materials conveniently and accurately. It can sustain learners' participation by using the multimedia integration of text, sound, animation, graphics and images to present the learning content in a multi-dimensional way. Matthews (1997) studied the interactive CD-ROM aided teaching software in reading comprehension training and pointed out that the learners in experimental group who read stories based on CD-ROM retold the stories far more completely than those in the contrast experimental group who read paper-based stories, which shows that learning based on CDROM can make learners realize text interaction, and actively build the text so as to comprehend the text. Nwaocha (2010) suggests that multimedia presentations can improve students ${ }^{6}$ understanding, enthusiasm, class attendance and satisfaction. For teachers, using multimedia in the instruction of English language creates learner-centeredness and helps students become active learners. This allows them to learn language according to their abilities, needs and preferences (Lu \& Liu, 2011). Sharma and Pooja (2015) conducted a study to investigate the effect of Computer Multimedia instruction on academic achievement in English language of $7^{\text {th }}$ class students. On the basis of the findings, it was established that subjects exposed to Computer Multimedia Instruction were higher on achievement in English in comparison to those exposed to traditional instruction.
From the findings of the above mentioned studies, it may be concluded that changing from a traditional chalk and talk method to Multimedia instruction significantly improves academic achievement while enriching class room teaching. Multimedia instruction can be perceived as a crucial instrument in the hands of the instructors to significantly enhance learning of English as a foreign language. There is a lot of scope for research by developing different instructional packages using multimedia for learners of different age groups at different places. So educationists need to develop better understanding of the conditions, circumstances, means and mechanisms through which an effective MBIP-ELS can be designed and incorporated in the teaching and learning of English as a Foreign language (EFL) to enhance the English language skills of learners.

\section{Theoretical Underpinning for designing an Effective MBIP-ELS}

Learning theory in the past decade has expanded dramatically because of the introduction of multimedia. The possibilities for learning and instruction through multimedia are nearly endless. But how can we best design an effective MBIP-ELS and avoid the many possible pitfalls? The answer to this question is provided by Richard E. Mayer, in his Cognitive Theory of Multimedia Learning that provides a framework to design an effective MBIP utilising the principles of cognitive science.

\section{Cognitive theory of multimedia learning}

The fundamental hypothesis of the Cognitive Theory of Multimedia Learning proposed by Richard E. Mayer was that multimedia instructional messages that are designed in the light of how human mind works are more likely to lead 


\section{International Journal of Science and Research (IJSR) \\ ISSN (Online): 2319-7064 \\ Index Copernicus Value (2013): 6.14 | Impact Factor (2014): 5.611}

to meaningful learning than those are not. He established the -mltimedia principle" that people learn more deeply from words and pictures than from words alone". It is based on following three cognitive science principles of learning:

1) Dual channel assumption- the human information processing system includes dual channels for visual/pictorial and auditory/verbal processing

2) Limited capacity assumption- each channel has limited capacity for processing

3) Active processing assumption- active learning entails carrying out a coordinated set of cognitive processes during learning (Mayer, 2005).

Multimedia researchers generally define multimedia as the combination of text and pictures; and suggest that multimedia learning occurs when we build mental representations from these words and pictures. Important to this assumption is the fact that these active verbal processes are more likely to occur when corresponding verbal and pictorial representations are in working memory at the same time" (Mayer, 2005). The words can be spoken or written; i.e. audio or text and the pictures can be in the form of graphical imagery including illustrations, photos, animation, or video streaming. Learners learn better when they engage in relevant cognitive processing such as attending to the relevant material in the lesson, mentally organizing the material into a coherent cognitive representation and mentally integrating the material with their existing knowledge. Therefore, simply adding pictures to words can not produce an effective instructional design to achieve maximum multimedia learning. Thus, Multimedia instructional design utilises the cognitive research to combine words and pictures in different ways to maximize learning. Within the theoretical framework of the cognitive theory of multimedia learning, active learning takes place when a learner selects, organizes and integrates corresponding verbal and non-verbal information. His study also shows that learners may engage in less in-depth learning with just text alone, not connecting what they have read with new or prior knowledge. Figure below is a graphical illustration of the steps in this theory.

\section{Cognitive theory of multimedia learning}

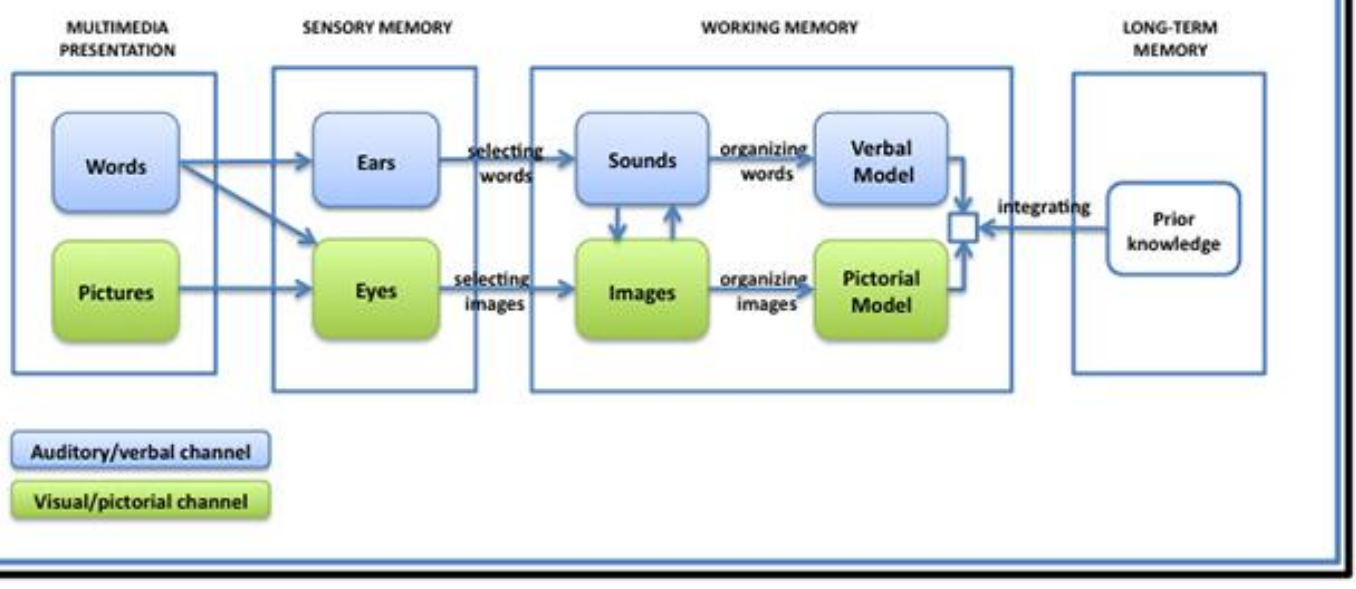

*source: Google Images - Cognitive Theory of Multimedia Learning.

There can be two ways of conceptualizing the difference between the two channels; one based on presentation modes and the other based on sensory modalities. The presentation mode approach focuses on whether the presented stimulus is verbal (such as spoken or printed words) or non-verbal (such as pictures, videos, animations or background sounds). In contrast, the sensory-modality approach focuses on whether learners initially process the presented materials through their eyes or ears. According to the sensory-modality approach, one channel processes visually presented materials and the other channel processes auditorily represented material. For the purposes of cognitive theory of multimedia learning, Mayer opted for a compromise in which he uses the sensory-modality approach to distinguish between *isually presented" material and auditorily presented" material as well as a presentation mode approach to distinguish between the construction of pictoriallybased" and *erbally-based" models in working memory.
Mayer argues that meaningful learning from words and pictures happens when the learner engages in five cognitive processes: 1. selecting relevant words for processing in verbal working memory 2 . selecting relevant images for processing in visual working memory 3 . organizing selected words into a verbal model 4 . organizing selected images into a pictorial model 5. integrating the verbal and pictorial representations with each other and with prior knowledge" (as cited by Sorden, 2012).

As part of his evidence-seeking efforts for the science of instruction, Mayer (2009) identifies the following twelve multimedia instructional principles which were developed from nearly 100 studies over the past two decades:

1) Coherence Principle - People learn better when extraneous material is excluded rather than included.

2) Signaling Principle - People learn better when cues that highlight the organization of the essential material are added. 


\section{International Journal of Science and Research (IJSR) \\ ISSN (Online): 2319-7064}

Index Copernicus Value (2013): 6.14 | Impact Factor (2014): 5.611

3) Redundancy Principle - People learn better from graphics and narration than from graphics, narration, and printed text.

4) Spatial Contiguity Principle - People learn better when corresponding words and pictures are placed near each other rather than far from each other on the page or screen.

5) Temporal Contiguity Principle - People learn better when corresponding words and pictures are presented at the same time rather than in succession.

6) Segmenting Principal - People learn better when a multimedia lesson is presented in user-paced segments rather than as a continuous unit.

7) Pre-training Principle - People learn more deeply from a multimedia message when they receive pretraining in the names and characteristics of key components.

8) Modality Principle - People learn better from graphics and narration than from graphics and printed text.

9) Multimedia Principle - People learn better from words and pictures than from words alone.

10) Personalization Principle - People learn better from a multimedia presentation when the words are in conversational style rather than in formal style.

11) Voice Principle - People learn better when the words in a multimedia message are spoken by a friendly human voice rather than a machine voice.

12) Image Principle - People do not necessarily learn more deeply from a multimedia presentation when the speaker's image is on the screen rather than not on the screen (as cited by Sorden, 2012).

Decisions about how to design a multimedia message always reflect an underlying conception of how people learn- even when the underlying theory is not stated. In short, the design of multimedia messages is influenced by designer's conception of how human mind works. For example when a multimedia presentation consists of a screen overflowing with multicoloured words and images- flashing and moving about- this reflects designer's conception of human learning. The designer's underlying conception is that human mind possesses a single channel and unlimited capacity and passive processing system. First, by not taking advantage of auditory mode of presentation, this design is based on a single channel assumption, i. e. all information enters the cognitive system in the same way regardless of its modality. Second, by presenting so much information, this design is based on unlimited capacity assumption i. e. human mind can handle unlimited amount of assumption. Third, by presenting many isolated pieces of information, this design is based on a passive processing assumption. In contrast to this, a multimedia instructional package based on Mayer's dual channel, limited capacity and active processing assumption and above listed 12 principles can be designed to maximise learning.

Thus, Mayer's multimedia learning theory offers an indispensable theoretical framework by providing clear information on how to design an effective multimedia instruction. A Multimedia-based Instructional Package for Enhancing English Language Skills (MBIP-ELS), designed intelligently keeping this framework in mind, can prove much more effective than the traditional — Galk to Talk" method. Incorporating multimedia for enhancing English Language Skills can face the challenge that the variety and range of English-learning situations in India pose in front of teachers and learners. In a scenario, where natural learning environment is nearly absent for a foreign language, such multimedia based inputs must be provided at least in the Indian classrooms, so that the language environment of disadvantaged learners can be enriched in more ways than one. The enhancement of English language skills using these strategies will remove the barriers to the access of higher education, employment opportunities and social responsibilities for Indian students. They will be able to assume more important roles at national and international fronts.

\section{References}

[1] Crystal, D. (2003). English as a global language. Cambridge: Cambridge University Press.

[2] Ethnologue, (21.12.2015). SIL International $\left(18^{\text {th }}\right.$ Edition). $\quad$ Retrieved from https://en.wikipedia.org/wiki/List of languages by tot al number of speakers

[3] Krashen, S.D. (1994). The input hypothesis and its rivals, Implicit and Explicit Learning of Languages, Academic Press, London: Ellis, N. Retrieved from CiteSeerX: 10.1 .1 .121 .728

[4] Kurrien, J. (2008). Marks Mask Incompetence: Our High School Students Have Low Levels of Learning. (Original unedited version of Leader Article In The Times of India", July 22, 2008). Retrieved from http://www.clrindia.org/downloads/Marks Mask Inco mpetence.pdf

[5] Matlin, M.W. (1989). Cognition. New York: Rinehart and Winston, Inc.

[6] Matthews, K. (1997). The influence of interactive CDROM storybook on reading comprehension. Journal of Research on Computerizing in Education, 263-70.

[7] Mayer, R. E. (2005). Cognitive Theory of Multimedia Learning, as retrieved on 22.12.2015 from http://files.onearmedman.com/fordham/mayer2005ch3.p $\underline{\mathrm{df}}$

[8] Mayer, R. (2005). Cognitive Theory of Multimedia Learning, Retrieved from https://www.google.co.in/search?q=cognitive+theory+o $\underline{\mathrm{f}+\text { multimedia }+ \text { learning }+ \text { richard }+ \text { mayer\&espv }=2 \& b i w=}$ $1352 \&$ bih $=639 \&$ tbm $=$ isch\&imgil $=0$ SZ0k6jfpDoVM $\% 253 \mathrm{~A} \% 253 \mathrm{~B}$ BNxS5k9RNNRtM $\% 253 \mathrm{Bhttp} \% 2$ 5253A\%25252F\%25252Fteorije-

ucenja.zesoi.fer.hr $\% 25252$ Fdoku.php $\% 25253$ Fid $\% 2525$ 253Dlearning theories\%25253Acognitive theory_of $\mathrm{m}$ ultimedia learning\&source $=\mathrm{iu} \& \mathrm{pf}=\mathrm{m} \& \mathrm{fir}=0 \mathrm{SZ}$-k6jfpD oVM\%253A\%252C_BNxS5k9RNNRtM\%252C_\&usg $=$ KgoN1gaE8G1dX1u1YyyGPgEFIPE\%3D\&ved $=0 \mathrm{a}$ hUKEwiMk6HZwcDKAhWVBY4KHcXCT0QyjcILg\&ei=p7jVsyjGZWLuATF afoAw\#imgrc $=0$ SZ0k6jfpDoVM $\% 3 \mathrm{~A}$

[9] Multimedia, (2014) Wikipedia. Retrieved from http://en.wikipedia.org/wiki/Multimedia

[10] National Knowledge Commission. (2007). Report to the nation 2006: Government of India. 


\section{International Journal of Science and Research (IJSR) \\ ISSN (Online): 2319-7064}

Index Copernicus Value (2013): 6.14 | Impact Factor (2014): 5.611

[11] Nwaocha, V.O. (2010). Enhance students' interest in mathematics via multimedia presentation. African Journal of Mathematics and Computer Science Research, 3(7), 107-113.

[12] Sharma, H.L. and Pooja (2015). Computer multimedia instruction versus traditional instruction: an experimental study. International Journal of Scientific Research, 740-742, 4(5).

[13] Sorden, S.D. (2012). Cognitive Theory of multimedia learning. $\quad$ Retrieved from http://sorden.com/portfolio/sorden_draft_multimedia20 12.pdf 